\title{
Saberes nas histórias de vida e na prática de formadores de professores
}

Knowledge in life stories and the practice of trainers teachers

Elizabeth Cardoso Gerhardt Manfredo ${ }^{1}$

Tadeu Oliver Gonçalves ${ }^{2}$

\section{Resumo}

Investigamos saberes de formadores de professores constituídos nas trajetórias de vida e suas repercussões na prática formadora. Utilizamos notas de campo e dados de questionários e entrevistas semiestruturadas de cinco formadores de professores de pedagogia de três universidades de Belém-Pa, Brasil. As biografias e outros dados permitiram interpretar experiências de constituição de saberes ao longo das trajetórias e refletir acerca da mobilização deles nas práticas formadoras. Connelly; Clandinin (2008), Nóvoa $(1992,2000)$ e Tardif $(2000,2002)$ e outros embasaram o estudo. Evidenciamos saberes construídos nas experiências narradas, com gênese na socialização pré-profissional, estímulo na formação profissional e sedimentação na prática profissional. Os saberes erigidos nas histórias definem a constituição profissional dos formadores, repercutindo nas suas práticas de formação para a docência em matemática dos anos iniciais, representando decisões, atitudes, posturas e abordagens na ação de formar outros professores.

Palavras chave: Saberes; Histórias de vida; Formadores de professores; Experiências.

\section{Abstract}

We investigate the knowledges of trainers teachers constituted in the life stories and repercussions in their practices.Was used field notes, questionnaires and interviews with trainers teachers of pedagogy from three universities in Belém-Pa, Brazil. The biographies and others informations provided the constructo about the experiences and the knowledges along the trajectories and practices. Connelly; Clandinin (2008), Nóvoa (1992, 2000) e Tardif $(2000,2002)$ are some authors utilized. It is concluded that knowledges constituted in the experiences has the genesis in the pre-professional socialization, are stimulated in the professional courses and sedimented in the professional practice of each trainer teacher. The knowledges erected in the course of their stories define their professional constitution. Those knowledges have repercussions in their training practices for teaching at elementary school and are representations of decisions, posture, attitudes and approaches in the action of training other teachers.

Keywords: Knowledge; Life stories; Trainers teachers; Experiences.

\footnotetext{
${ }^{1}$ Universidade Federal do Pará | bethma@ufpa.br

2 Universidade Federal do Pará | tadeuoliver@yahoo.com.br
} 


\section{Introdução}

Pesquisas e discussões em torno da formação e da prática do professor universitário são importantes na produção de conhecimentos que possam contribuir com o processo de superação dos desafios impostos à prática formadora no ensino superior. Sendo assim, este estudo focalizou saberes de professores formadores atuantes em cursos de pedagogiaresponsáveis pela formação profissional de outros professores para o ensino de matemática nos anos iniciais de escolaridade- indagando que saberes são construídos nos percursos de formação desses professores e como repercutem na prática formadora que realizam. Diante disso, cumpriu o objetivo de investigar saberes de professores formadores constituídos nas suas trajetórias de vida e suas repercussões na prática formadora.

Para tal empreendimento, construímos referências teóricas, a partir de estudos da literatura disponível sobre formação de professores, que trata do saber docente ou saber de professores (TARDIF, 2002; GAUTHIER et al) ou, nos termos de Shulman (2005), do conhecimento de base do professor, este aqui adotado como saberes docentes. Além desses, recorremos a pressupostos da pesquisa narrativa (CONNELLY; CLANDININ, 2008) e a estudos (auto) biográficos (NÓVOA, 2000; MOITA, 2000; ABRAHÃO, 2006; DELORY MOMBERGER, 2008), que fundamentam vários aspectos deste estudo narrativo, o qual se mostra interessante na construção e na reconstrução do próprio sujeito, através do objeto da narrativa e das reflexões dele advindas.

Um aspecto importante das experiências forjadas na trajetória ou histórias de vida do professor refere-se às perspectivas da valorização de sua pessoa (NÓVOA, 1992, 2000). Tal componente de subjetividade e pessoalidade tem implicações na constituição de seus saberes no seu caminhar de vida e profissão. Esses saberes são primordiais à função exercida pelo docente na sociedade o que enseja sua explicitação em estudos nos quais o professor seja reconhecido como detentor e mobilizador de saberes ao longo da formação e da prática (NÓVOA, 1992; SHULMAN, 2005; TARDIF, 2002).

Diante do exposto, apresentamos este texto o qual apresenta inicialmente discussões acerca dos saberes de professores, pontuando aspectos da literatura sobre a temática e suas relações com outros referenciais concernentes à formação de professores; em seguida apresentamos as definições metodológicas assumidas neste estudo narrativo; e finalmente, destacamos das análises os pontos significativos evidenciados sobre os saberes e suas expressões ao longo das trajetórias dos formadores de professores participantes do estudo.

\section{Aspectos teóricos e reflexivos envolvendo saberes de professores}

Os saberes dos professores modelam-se nos percursos da história pessoal e profissional. Nesse sentido, ocorrem desde tempos anteriores à profissionalização docente, isto é, desde a fase pré-profissional de sua trajetória, e vão se consolidando ao longo desse caminhar ao lado de outros que vão sendo incorporados. As influências sofridas por tais saberes no transcurso das histórias de vida impactam decisões, atitudes e mecanismos de ação do professor, denotando que o modo como ocorrem a socialização, o tipo e a qualidade das experiências vividas dentro e fora do ambiente escolar explicam a forma como é, faz e pensa a própria ação docente (LORTIE. 1975; NÓVOA, 2000, SACRISTAN, 1995, TARDIF, 2002). 
Tardif (2002) assinala, nesse sentido, que o saber docente é composto de vários saberes oriundos de diferentes fontes e produzidos em contextos institucionais e profissionais variados e é marcado por características da pessoa do professor, incluindo concepções, crenças e tudo que possa tê-lo constituído ao longo de sua história de vida. Assim, cabe afirmar que "uma parte importante da competência profissional dos professores tem raízes em sua história de vida" (TARDIF, 2002, p. 69) e durante a qual inexistem lugares e tempos únicos nos quais possam ser construídos e reconstruídos os saberes dos professores, longe disso, são múltiplos e dinâmicos, assim como são nossas vidas (PEDROSA; LEITE; ARAGÃO, 2012).

Baseados em Tardif (2002); Shulman (2005); Gauthier et al (2006), envolvendo o pensamento, o conhecimento ou saber do professor, assumimos a noção de saber análoga a de conhecimento, entendendo-a como o conjunto de manifestações racionais justificáveis de algum modo e que fazem algum efeito no indivíduo, na forma de saber, de saber-fazer e saber-ser, sendo isso considerado saber ou conhecimento do professor.

Tardif (2002) amplia a visão sobre os saberes docentes e as fontes desses saberes, incluindo os pessoais, que se originam na formação escolar anterior à formação profissional. Desse modo, vai além do que Shulman (2005) define como conhecimento/saberes e suas fontes. Os saberes pessoais, bem como os demais destacados por Tardif (2002), têm fontes diversas, desde a convivência familiar, passando pela vida escolar que incluem ambientes e convivências educativas informais, indo até a experiência profissional do ofício docente. Como aludido, o ofício de ensinar, nos termos de Pedrosa; Leite; Aragão (2012, p. 164), trata-se de um "processo complexo, multirreferencial, que implica diferentes saberes profissionais, os quais devem ser mobilizados para que as diversas ações inerentes a esta prática de ensino se efetivem.".

Com essa visão de saberes, importa revelar crenças e concepções apresentadas por professores, com vistas a conhecer seus processos formativos. Lortie (1975), em estudo sobre a socialização prévia no ensino, evidencia que professores desenvolvem padrões mentais, crenças sobre o ensino, a partir do período prolongado de observação como alunos. Tal aprendizagem por observação ocorre de modo não intencional e se integra às estruturas cognitivas e emocionais dos futuros professores de modo inconsciente, chegando a criar expectativas e crenças de difícil remoção. Isso exige pensar a formação docente, de modo a criar modos de promover confrontos de tais saberes, buscando fortalecer os desejáveis, ou possibilitar mudanças de ideias cristalizadas.

Tal perspectiva formativa deve ser assumida, dado que os alunos, por meio da observação, aprendem com seus mestres, dando pistas de que o modo como esses professores são socializados na própria formação profissional repercutirá especialmente na maneira como serão docentes e, por conseguinte, na forma de agir com seus alunos que, na mesma lógica, verão nele um modelo a seguir. Nesse sentido, Serrazina (2002) refere que o formador- ao assumir princípios formativos ao seu modo de ensinar e socializar isso com seus alunos- deve promover nos futuros professores o desenvolvimento consciente desse modelo didático aprendido, isto é, uma formação pautada na reflexão advinda da experiência, esta sendo campo fértil de produção de saberes.

Shulman (2005), ao tratar sobre a experiência, afirma que aprendemos pensando sobre nossas experiências que, narradas, se tornam experiências de segunda ordem. Ao defender a importância do estudo de caso na formação, ele diz que o caso é uma versão relembrada, recontada, reexperenciada e refletida de uma experiência direta. Portanto, o processo de 
relembrar, recontar, reviver e refletir é o processo de aprendermos pela experiência. Diante disso, cabe pensar na importância e no potencial da experiência refletida para a constituição do saber docente.

\section{Delineando a investigação narrativa sobre saberes de formadores de professores}

A indagação envolvendo saberes de professores no percurso das histórias de vida, como já mencionado, coloca-se como norte ao objetivo de investigar saberes de professores formadores constituídos nas suas trajetórias de vida e as repercussões na prática formadora. Diante disso e de opções de posições teóricas assumidas, em termos de modos de ver, de compreender e de conduzir a investigação, recorremos à abordagem qualitativa nos termos de Bogdan; Biklen (1994) e na pesquisa narrativa de cunho autobiográfico, buscando perceber os aspectos sobre os professores formadores participantes do estudo, na forma como experimentam, vivenciam e expressam suas vivências, para assim melhor conhecê-las, interpretá-las, atribuindo significados relevantes ao seu processo de formação e prática.

Para tanto, lançamos um olhar sobre histórias alheias capazes de refletir as próprias, e ainda as de outrem (DELORY MOMBERGER, 2008) e delas buscamos resgatar a essência apreendida capaz de revelar aspectos formativos de cada um dos participantes. Estes que, por meio de suas narrativas, capturadas em entrevistas e outras interações, nos contam suas histórias de vida e formação (NÓVOA, 2000; MOITA, 2000). Com os dados, tecemos um constructo verossímil para a compreensão do fenômeno estudado.

Ao contar nossa história revelamos quem somos, autoconhecemo-nos e conhecemos aos outros. Assim, como pesquisadores fortemente autobiográficos, os pesquisadores narrativos experimentam o mundo por meio da narrativa, no sentido de Connelly; Clandinin (2008), Larrosa (2002) e Benjamin (1994), que reconhecem nos estudos narrativos o envolvimento dos pesquisadores com seu objeto no sentido da projeção de si no contexto em que o objeto se insere.

Nessa direção, Benjamin (1994) assinala o papel da narrativa como forma de expressão da experiência humana, portanto, a mais apropriada maneira de intercambiar experiências, haja vista refleti-las. Para ele, à narrativa não interessa a transmissão em si do narrado, mas sim particularidades daqueles que narram, isto é, suas marcas e identidade narrativa. Com isso, permite a reflexão de que ao narrar o fazemos, segundo um modelo artesanal no qual utilizamos a matéria-prima da experiência (nossa e alheias) e a transformamos num produto sólido, útil e único. E isso se torna importante e desejável em processos de investigação nos quais se recorra à narrativa.

As narrativas, portanto, representam um modo de produzir significados a experiências passadas e presentes, tendo em vista, potencialmente, ensejar ou revelar novas experiências (BENJAMIN, 1994). Os adeptos das análises e interpretações narrativas não apenas estudam como as pessoas percebem o mundo por meio de suas histórias narradas, como também valorizam os efeitos delas nos caminhos vividos e experienciados pelo narrador.

A investigação, assim conduzida, expressa a potencialidade da narrativa autobiográfica na medida em que, conforme Abrahão (2006, p. 150), a narrativa "contém a totalidade de uma experiência de vida que é comunicada ao investigador, não sem que, no justo 
momento da narração, se ressignifique o (os) acontecimento(s) narrado(s)". A (re) construção de sentido de nossas vidas, ou um processo de reconstrutividade da memória (ABRAHÃO, 2006) é um processo interminável de ouvir e ler histórias, de mesclar histórias, de contrapor umas histórias a outras.

Participaram da pesquisa cinco professores universitários formadores de outros professores, na área de matemática, de cursos de pedagogia de três universidades de Belém-PA, a saber: Universidade Federal do Pará (UFPA); Universidade do Estado do Pará (UEPA) e Universidade da Amazônia (UNAMA). As identidades dos participantes foram preservadas, sendo atribuídos a eles os nomes fictícios de Mauro, Orlando, Rômulo, Vinícius e Sandro. São formadores relativamente jovens cuja média de idade é de 42 anos. A análise do material na pesquisa como um todo foi estruturada segundo as narrativas e demais informações obtidas através das entrevistas textualizadas, de relatos escritos, de questionários, das notas de campo e de material documental dos participantes. Devido ao espaço reservado para este texto, faremos a apresentação de análises referentes, principalmente, ao conteúdo das entrevistas - a partir das quais foram produzidas as histórias de vida, desde a socialização primária até a socialização profissional - com relatos sobre suas práticas, assim como a textos nos quais responderam a uma pergunta narrativa.

Nesse propósito, evidenciamos percursos e implicações de seus desenvolvimentos rumo à docência nos quais observamos que a gênese do processo de desenvolvimento da docência em matemática ocorre com influência de momentos da socialização familiar, principalmente, a escolar inicial até o ensino médio, e ainda nas opções primeiras de formação profissional. Também é dada ênfase à socialização profissional e ao exercício do magistério superior na função exercida de formar professores dos anos iniciais nas universidades onde atuam.

\section{Expressões de saberes nas trajetórias dos formadores}

\section{-Saberes da docência em matemática na socialização pré-profissional}

Analisamos as biografias dos participantes, buscando compreender nelas fatores e implicações na opção pela docência em matemática, destacados nos percursos, e que evidenciam saberes em gênese na trajetória pré-profissional, com representações construídas dos próprios percursos formativos deles.

Os saberes concernentes à docência em matemática são manifestados em gênese entretecidos nas experiências vividas nesses percursos formativos, durante os quais sentiram admiração, respeito, raiva, decepção, assim como, motivaram-se, desenvolvendo aptidões e necessidades objetivas de lidar com conhecimentos matemáticos diversos capazes de despertar apego e permanência, nesse campo específico, mediante ainda práticas antecipadas exitosas de ensinar assuntos de matemática.

Cabe destacar nas histórias de infância até a juventude, quando se formam professores, inclinações pessoais naturais ou ambientais relativas ao conhecimento matemático, como as de Vinícius que analisa como algo natural o interesse e a facilidade em relação à disciplina matemática:

Interessante [que] era algo natural, eu apenas gostava [...] quando eu estava na sexta série, os meus colegas tinham muita dificuldade em 
aprender matemática e, na verdade, era a única matéria em que eu tinha muita facilidade (Ent., Vinícius, 2011).

Também interesse e desempenho são expressos por Rômulo e Orlando, ao evocarem a condição de alunos exemplares de matemática, durante a escolaridade básica, feito atribuído ao auxílio do pai bancário, no caso de Rômulo: "por meu pai ter afinidade com a área de exatas, nunca apresentei dificuldade em matemática. Ele trabalhava no banco, então me ensinou matemática. Sempre fui um dos melhores alunos de matemática". (Ent., Rômulo, 2011). Do mesmo modo, pela influência do pai mestre de obras, no caso de Orlando, como ele narra: nas disciplinas de exatas no ensino médio, eu me dava muito bem [e também] por causa do meu pai [que] é mestre de obras até hoje. Constrói de tudo [...] eu ficava impregnado disso, ia muito para obra com ele (Ent., Orlando, 2011).

Os saberes de conteúdos matemáticos constituídos em suas experiências diversas e na escolarização fundamental são empregados por eles para o alcance de outros patamares formativos em nível médio e depois superior, bem como são a base para o início do exercício tácito do saber pedagógico da docência em matemática, que os direciona a uma prática docente correlata e, por conseguinte, a uma formação profissional nos cursos escolhidos. Vale lembrar que tais cursos não foram unanimidade em termos da docência como formação profissional. Apenas Sandro escolhera esta formação, os demais, de início, pleitearam cursar engenharia. Vinícius desistiu devido a não aprovação e iniciou então a licenciatura. Rômulo, Orlando e Mauro foram aprovados em cursos de engenharia dos quais desistiram e ingressaram, finalmente, no curso de licenciatura.

O gostar de matemática e desempenho na disciplina é um aspecto interessante no estudo acerca do início do percurso docente dos formadores. Remete-nos à tendência natural e cultural de lidar com o conteúdo matemático, às experiências significativas nesse âmbito e a partir delas as ancoragens realizadas a fim de representarem esse conhecimento, tornando-o acessível à aprendizagem de outras pessoas.

Cada um deles constrói esses saberes relativos à matemática e à sua didática, mediante influências diversas de relações com pessoas da família, professores marcantes e contextos práticos de aplicação desses saberes, durante a trajetória pré-profissional (LORTIE, 1975; TARDIF, 2002). Relações ocorridas em suas infâncias, em momentos da socialização primária, mormente da socialização escolar, na aprendizagem por observação. Mauro, ao lidar aos oito anos com conhecimentos aritméticos e geométricos, trabalhando para ajudar a família, descreve seu envolvimento prático com a matemática, empregando assuntos estudados em âmbito escolar, em que era bom aluno, inclusive de matemática. A articulação teoria do conhecimento escolar e prática cotidiana permite-Ihe estabelecer uma relação com o saber que facilitará seu percurso escolar e acadêmico. Os saberes envolvendo conhecimentos básicos de construção civil, desenvolvidos durante o ensino médio, também serão incorporados ao seu repertório de saberes, consolidando-o.

Vinícius, a exemplo de Mauro, desde cedo manifesta uma relação prazerosa com a matemática. Gostava dos conteúdos com os quais tinha facilidade e isso foi percebido por ele, por seus colegas e pela professora da $6^{a}$ série que o incentivou, segundo seu relato:

Quando as aulas terminavam, meus colegas por saberem que eu tinha facilidade, pediam para eu explicar para eles o que a professora tinha explicado, porque não tinham entendido [um dia] a professora, depois de me observar, veio e disse pra mim que eu deveria ser professor de matemática (Ent. Vinícius, 2011). 
Sua facilidade e sua necessidade de fazer-se entender pelos colegas incentivam-no a desenvolver, a exemplo de Mauro, estratégias particulares de ensino do conteúdo, agradando seu público e automotivando-se no sentido da docência, ainda implícita naquela altura.

Tal destreza em matemática foi observada também na história de Rômulo, que, desde criança, se mostrava um excelente aluno, contando com auxílio do pai bancário. A mesma relação de envolvimento teórico-prático de Vinícius também foi notada nele, com suas experiências didático-pedagógicas como catequista, aliada ainda ao modelo marcante do professor da $8^{a}$ série, por quem tinha admiração pela forma clássica de ensinar matemática.

Por sua vez, Sandro também gostava de matemática e tinha sucesso com os números desde a infância. Ele buscou associar esses conhecimentos a atitudes investigativas pessoais, preteridas quando de seu ingresso no curso de administração e, depois, retomadas quando iniciada a prática leiga, passando a ter necessidade de articular os assuntos dominados, e dos quais gostava, com a necessidade de socializá-los com os alunos. Do mesmo modo que Orlando, Sandro necessitava de outros saberes que o ajudassem nesse sentido, daí também o interesse que passou a nutrir pela licenciatura.

Diante do exposto, percebemos que o gostar do conteúdo matemático e, por conseguinte, ter facilidade com ele, foi algo comum em suas socializações primárias e escolares. Nesse sentido, o saber matemático foi se manifestando naturalmente, ao passo que the permitiu desenvolver suas capacidades potenciais de uso da linguagem para lidar com a matemática (DEVLIN, 2010). Todos com suas capacidades individuais puderam mediante experiências com pai, irmão, professores - construir suas "casas" acerca da matemática, dado que "compreender a matemática é como construir uma casa, e, daí por diante, saber se virar dentro dela" (DEVLIN, 2010, p. 148). Dessa afirmação, cabe deduzir que os formadores tiveram motivações pessoais, estímulos externos e orientações necessárias para aproveitar e exercitar suas destrezas matemáticas aprimoradas em suas experiências.

Além do saber do conteúdo matemático, o saber pedagógico do conteúdo (SHULMAN, 2005) merece destaque. É através dele que se chega à compreensão de como determinados temas e problemas se organizam, representam e se adaptam aos diversos interesses e capacidades dos alunos. Esse saber tem relação com a forma como os professores pensam que têm de ajudar os alunos a compreender determinado conteúdo. Inclui as maneiras de expor e formular o conteúdo para torná-lo compreensível.

Os formadores viveram essa mobilização de modo incipiente no momento em que recorrem a métodos próprios, destrezas pessoais e analogias particulares, de sua pessoa no contexto referente a cada experiência de vida. Nelas puderam vivenciar a construção desse saber, ainda na prática leiga, quando não tinham a formação profissional, e quando passam a fazer isso concomitante à formação nos cursos profissionais de licenciatura, conforme seus relatos, denotando uma coerência pragmática e biográfica da constituição desses saberes (TARDIF, 2002, TARDIF; RAYMOND, 2000).

Esse desenvolvimento incipiente da docência através da prática do saber pedagógico de matemática mostra-se em processo no caso de Vinícius. Ele, desde a adolescência, praticava a docência com os colegas e evidencia tal saber ao modular sua intervenção, esforçando-se para entender o que tornava algumas ideias difíceis à compreensão dos alunos e que tipos de exemplos, analogias e problemas podiam torná-las mais claras para eles (SHULMAN, 2010). Em seu relato, ensinando os colegas, ao dizer que "[Eu] fazia desenho no quadro [...], explicava de uma maneira, não entendeu, então passava para outra 
maneira de explicar, e às vezes precisava colocar coisas práticas" (Ent. Vinícius, 2011) revela a antecipada constituição formativa e como o saber pedagógico da matemática se impunha em sua trajetória pré-profissional.

Tal saber pedagógico do conteúdo mobilizado de modo informal também era expresso por Mauro quando ministrava, durante o curso de engenharia, aulas de matemática a professoras dos anos iniciais, as quais buscavam reforço em razão das dificuldades sentidas. Era elogiado bastante pela linguagem empregada para facilitar a compreensão do conteúdo.

Era procurado por algumas professoras para 'tirar' dúvidas de assuntos matemáticos que tinham de ensinar e não sabiam direito como fazê-lo [...] a maioria daqueles alunos-professores tinha dificuldades com os conteúdos matemáticos tanto em seu aspecto conceitual [quanto] procedimental. (Texto, Mauro, 2010, destaque dele).

A experiência da docência matemática de ambos, tal qual expressam, parece encorajálos ainda mais para confirmar tal docência. Agem antecipadamente como professores e aprendem melhor a ministrar aulas, ministrando-as, ensaiando posturas docentes necessárias a seus objetivos, ainda inconscientes naquele momento de sua vida. Eles, como membros de uma família e nas relações de convivência social e escolar, tiveram modelos de inspiração que os aproximaram do saber matemático, do ensinar matemática e da formação para tal.

Enfim, cabe dizer que o conteúdo apresentado das biografias e das reflexões associadas corrobora a assertiva preconizada de que os saberes dos professores têm origem em contextos sociais anteriores à carreira docente propriamente dita. Isso significa que, na família do professor, na escola que o formou ou em aspectos de sua cultura pessoal e ainda de professores que os inspiram (LORTIE, 1975; TARDIF, 2002; TARDIF; RAYMOND, 2000) se encontram explicações que permitem compreender certos comportamentos e atitudes, bem como localizar passagens de vida que, no caso dos cinco professores formadores, demonstraram que os saberes relativos à matemática e à sua docência foram se manifestando e direcionando um saber e um saber-fazer docente.

Com efeito, é impossível estudar os processos de formação de professores desconsiderando suas histórias. Por isso, cabe reiterar que as biografias formativas dos formadores deste estudo revelaram que nessa parte inicial de suas histórias- isto é, na socialização pré-profissional- está a gênese da docência em matemática e a base estruturante em constituição da formação deles como formadores de outros professores, que continuará seu processo de consolidação nos demais momentos de socialização.

\section{-Saberes no percurso da socialização profissional}

Dando sequência às suas histórias, passamos a descrever biograficamente momentos e experiências marcantes dos formadores até a prática de formação em matemática de professores dos anos iniciais, observando indícios dessas experiências no que relatam das práticas formadoras. Ao final, segundo suas narrativas, sintetizamos um conjunto de saberes que foram se constituindo ao longo das trajetórias de vida e que repercutem nas ações desenvolvidas como formadores.

Diante dos relatos sobre o período de formação profissional nos cursos de licenciaturas, cabe dizer que, apesar de todos terem passado pela formação inicial em 
matemática e optado pela docência antes ou durante o curso, os problemas formativos enfrentados, tais como falta de objetivos ou clareza nos cursos, prevalência de uma formação especialista em detrimento de uma formação para a docência; a didática e a formação de seus professores formadores, dentre outros, são indicativos de que, assim como eles, muitos professores em formação inicial vivem experiências pouco significativas em termos da docência como profissão.

Tardif (2000), ao refletir sobre essa problemática, aponta que os cursos de formação para o magistério são globalmente idealizados, segundo um modelo aplicacionista do conhecimento, no qual prepondera o estudo dos assuntos numa lógica disciplinar e não numa lógica profissional. Tal modelo formativo é criticado por Roldão, citada por Flores (2010), a qual se refere a um paradigma de formação inicial de lógica aditiva ou combinatória. Nesses modelos, há uma flagrante dissociação entre pesquisa, formação e prática profissional que depõe contra a qualidade da formação no magistério. Esse descontentamento com a formação inicial aparece nos relatos dos formadores:

O curso que fiz não me orientou a ser professor, não percebi assim (Ent., Mauro, 2010).

[os professores do curso] não se preocupavam muito em como ensinar a matemática; queriam que a gente aprendesse a matemática pura sem se preocupar em dar significado ao processo de ensino ou de aprendizagem. (Ent. Vinícius, 2011).

[as aulas eram das disciplinas pedagógicas] eu achava meio soltas, livres demais, não via grandes contribuições. Passei a aprender melhor estudando para concurso, estudando pra dar aula; já depois de formado (Ent. Rômulo, 2011).

A falta de objetivos formativos em cursos de licenciatura em matemática também é observada em Belo (2012), Gonçalves (2000) e em outros estudos dedicados ao tema da formação de professores de matemática. Flores (2010), ao discutir sobre a formação inicial, observa que ensinar, além de implicar a "aquisição de destrezas e de conhecimentos técnicos", também pressupõe um processo reflexivo e crítico (pessoal) sobre o que significa ser professor e sobre os propósitos e valores implícitos nas próprias ações e nas instituições onde se trabalha.

Em direção similar, Tardif (2000) afirma que o conhecimento da matéria ensinada e o conhecimento pedagógico são conhecimentos importantes, mas, certamente, estão longe de abranger todos os saberes profissionais dos professores. Ressalta a necessidade de articular teoria e prática e de investir em desconstruções de crenças cristalizadas, haja vista que os cursos pouco ou nada têm abalado tais crenças constituídas na aprendizagem por observação (LORTIE, 1975; TARDIF, 2002).

Os professores formadores se referem a outras experiências que assumem papel fundamental em suas constituições. Os relatos a seguir expressam isso.

[...] aspectos relevantes da minha formação acadêmica se dão no mestrado. As atividades desenvolvidas no mestrado, e agora no doutorado me marcaram muito. (Ent., Mauro, 2010).

[como bolsista do projeto...] a gente foi para salas de aula em Belém; eram escolas públicas do estado e de bairros periféricos [...] o que eu faço 
hoje no curso de pedagogia como formador, minhas preocupações com a aprendizagem, se devem fortemente à minha experiência na rede municipal com a formação de professores nas séries iniciais.(Ent., Orlando, 2011).

[...] foi [a especialização em ensino de ciências] que me deu ferramentas na verdade para poder repensar minha prática (Ent., Vinícius, 2011).

$\mathrm{Na}$ especialização teve um fato interessante. $\mathrm{O}$ professor da Educação Matemática que ministrava instrumentação para o Ensino da Matemática. Foi [em quem] baseei bastante em termos da parte de Metodologia de Ensino, eu peguei um pouco do modelo dele de aula. Então análise de livro didático, textos sobre tipos de educação. Foi ele quem me animou a fazer pós-graduação na área de Educação Matemática (Ent., Rômulo, 2011).

[no NPADC] na época, abriram as ideias, permitiram a gente ter acesso [a essas discussões sobre o ensino]. Desde o início quando participava dos eventos durante a graduação, [tais como] CNNECIM [Congresso NorteNordeste de Educação, Ciências e Matemática] já estava envolvido [...] trabalhava com o professor desde os anos 80 nos cursos que a secretaria de educação oferecia [e] eu ia ministrar cursos em projetos que participei, [também] quando a SBEM [Sociedade Brasileira de Educação Matemática] foi fundada eu estava lá, quando a Sociedade Brasileira de História da Matemática foi fundada eu estava lá [...] eu gostava. (Ent., Sandro, 2011). [Busca pela formação pós-graduada em educação para] ver os problemas mais imediatos, problemas ligados ao ensinar um pouco melhor, como formar um pouco melhor o professor. (Ent., Sandro. 2011).

É possível observar que as experiências vivenciadas durante momentos de formação continuada- em termos de pós-graduação ou mesmo experiências profissionais e acadêmicas durante o curso de licenciatura, não necessariamente nas aulas- tiveram muita importância para eles, a ponto de serem evocadas narrativamente. Isso demonstra o quanto tais experiências foram importantes e os transformaram (LARROSA, 2002), ao longo dos percursos de vida, contribuindo na constituição de saberes que subjazem às práticas formadoras (TARDIF, 2002; TARDIF; RAYMOND, 2000), no processo de formação para a docência em matemática de professores dos anos iniciais.

\section{Expressões de saberes na prática profissional formadora}

Nesse ponto, trazemos as práticas formadoras e a maneira como os formadores de professores as representam no ensino superior, expressando os saberes produzidos nas histórias, que, de alguma forma, repercutem no modo como desenvolvem a ação pedagógica, ao formar o professor que ensinará matemática nos anos iniciais. Nos relatos, os formadores evocam dificuldades dos alunos, que são os professores em formação inicial, com relação aos conhecimentos da matemática necessários à prática profissional que assumirão. Ao lado disso, encontra-se a resistência afetiva ou mesmo desgosto em relação à área, algo destoante do perfil de aptidão apresentado por seus formadores, segundo suas biografias mostraram. No caso de Mauro, já tinha certa representação desses comportamentos, quando ministrava o reforço matemático a professores, antes de se 
formar professor. Esse saber sobre as dificuldades, ele traz para sua prática e recorre a ele para desmistificar os medos e os equívocos dos alunos.

Assim, declara buscar traduzir para os alunos conceitos aparentemente difíceis de ser entendidos e transportados à realidade exterior à matemática. Ele diz: "quando eu vou dar simetria de reflexão, digo: vocês sabem a listela? E a maioria não sabe o que é listela, e eu digo: listela que vocês têm no banheiro, na cozinha, aquele azulejo [...]".(Ent., Mauro, 2010). Quando os alunos finalmente percebem a relação com algo conhecido, interessam-se ainda mais em aprofundar a discussão e isso facilita suas aprendizagens.

Dificuldades mencionadas por Mauro, também o são pelos demais. No caso de Rômulo, frente à resistência dos alunos e às dificuldades matemáticas, vê necessário que exercitem uma melhor disposição em termos da própria formação, visando a avanços nos alunos quanto à capacidade de representação de dados geométricos, essa avaliada como problemática na maioria dos alunos com quem tem interagido. Evidencia esses avanços a partir de sua reflexão sobre a ação pedagógica:

De uma turma pra outra eu procuro, não de forma bem organizada, a cada vez que eu implemento essa atividade[manipulação de instrumental matemáticos] eu procuro melhorar uma coisa que não fiz na anterior [...]então eu visualizei depois de um certo tempo de ocorrido a atividade como é que eles conseguem representar e eu achei o resultado bem positivo nesse aspecto porque eles conseguiram fazer, conseguiram representar, medir...Teve gente que eu tive de ensinar como é que usava o transferidor, [mas] a grande maioria conseguiu medir [então] ficou bem legal, pelo menos nesse aspecto [da abstração, da representação]eles melhoraram bastante.(Texto, Rômulo, 2011).

Oliveira (2007), em pesquisa com formadores, retrata obstáculos similares enfrentados pelos graduandos, que são também apontados por Manfredo (2004), em estudo com professores leigos em formação no curso de pedagogia. Ambas evidenciam a correlação entre o mau desempenho como aluno em matemática e a qualidade e quantidade de aulas de matemática realizadas anos iniciais. A fala de umas das informantes demonstra o que a resistência ou desinteresse pela matemática pode causar ao ensino: "outra professora assim se coloca: 'minha professora nas séries iniciais não gostava muito de matemática, então ela preferia ensinar a ler e escrever e só uma vez na semana tínhamos aula de matemática'" (G, 2003). (MANFREDO, 2004, p.04).

Curi; Pires (2008), em ampla pesquisa sobre estudos tratando do tema da formação de professores polivalentes, apontam grandes dificuldades quanto ao conteúdo, ao currículo e à didática nos anos iniciais, o que tende a melhorar, com a reflexão teoria e prática e com atividades investigativas nos processos de formação desses professores, seja inicial ou continuada.

A constatação unânime dos professores formadores dessas lacunas em seus alunos obriga-os a desenvolver esquemas práticos e estratégicos, na acepção de Sacristán (1995), para superarem as dificuldades e ensaiarem relações afetivas com a matéria, uma vez que terão de ensiná-la. Nesse sentido, vale a opção pelo estudo dos parâmetros curriculares, aulas-passeio contextualizadas, atividades práticas e teóricas, emprego de material concreto, atividades orientadas, contextualização histórica, filosófica, práticas de iniciação à pesquisa etc. Todas essas práticas evidenciadas no contexto da ação pedagógica de Mauro, Orlando, Rômulo, Vinícius e Sandro. 
As tarefas propostas por eles buscam minimizar as dificuldades observadas e assim possibilitar uma formação matemática nos termos que cada um defende. Com efeito, atentam para conteúdos específicos integrados ao método, com estímulos à reflexão por meio de questões filosóficas histórias, psicológicas, psicopedagógicas e científicas que demonstram dominar; para tal, recorrem a saberes constituídos em seus percursos préprofissionais e profissionais.

Em termos da iniciação à pesquisa, Sandro, Rômulo e Vinícius demonstram trazer de suas formações e das experiências pregressas ações de inserção de atividades investigativas na prática formadora. Revelam buscar transpor para suas práticas aquilo que desenvolveram como saberes em momentos de suas formações pós-graduadas e que se mostra promissor e importante aos alunos universitários que estudam a docência em matemática e que precisam fazer isso no contexto de produção científica na área de educação matemática.

Desde que implementei [a escrita de] artigo, eu tenho alguns resultados. Os alunos retornam comigo para melhorar o artigo e mandar para eventos. Então eu já tive 4 ou 5 alunos de turmas anteriores que [se empenharam em] mandar para eventos. Apesar de saber que alguns artigos não tem perfil para ser publicado, eu não desencorajo, eu reoriento, ajeito aqui, às vezes até eu mesmo pego e melhoro o texto pra não ficar muito complicado. Acho um aspecto positivo isso de quererem [publicar], ainda mais no curso de pedagogia que historicamente tem afastamento, principalmente em matemática. Eu acho interessante que eles acabam publicando ou tentando publicar em educação matemática (Texto, Rômulo, 2011).

A seu modo, cada um dos formadores sinaliza realizar processos pontuais ou sistemáticos de práticas de formação de um professor pesquisador. Autores como Gonçalves; Gonçalves (1998), Manfredo (2004) apontam e defendem tal tendência formativa com ressonância nos estudos sobre a pessoa do professor, seu desenvolvimento profissional, práticas emancipatórias e concepções envolvendo reflexão e pesquisa.

Além dos pontos evidenciados de aspectos observados na prática dos professores formadores, apresentamos uma síntese dos saberes constituídos ao longo dos percursos, um conjunto de saberes dos professores, segundo as fontes de aquisição deles para esta pesquisa. Tal síntese partiu das categorias organizadas por Tardif; Raymond (2000, p. 215) e incluem: 1-saberes pessoais, os oriundos da formação para o magistério; 2-saberes provenientes dos programas e livros didáticos utilizados no trabalho, e 3-saberes da própria experiência na profissão, na sala de aula e na instituição onde atua.

Assim, seguem os saberes percebidos ao longo da análise das biografias de formação e relatos da prática formadora. Os saberes pessoais: saber buscar/mobilizar conhecimentos com curiosidade e autodidatismo; saber gostar e lidar com os conhecimentos matemáticos; saber ensinar matemática; saber sobre dificuldades de professores dos anos iniciais; saber contextualizar conteúdos matemáticos; saber criticar modelos curriculares e práticas docentes; saber valorizar regras e propriedades matemáticas; saber sobre o modelo pedagógico de debate e discussão e suas críticas.

Em termos dos Saberes oriundos da formação profissional para o magistério: saber problematizar os assuntos; saber sobre o currículo de matemática para os anos iniciais; saber de uma pedagogia racional; saber não dissociar conteúdo e método; saber fazer 
analogias e contextualizar; saber sobre processos de aprendizagem em matemática; saber da formação pela e para a pesquisa; saber usar metodologias diversificadas (manipulação de material, atividade prática em grupos, seminários, pesquisas de campo, exercícios, provas); saber da reflexão sobre a própria prática; saberes referentes à didática (planejamento, organização de aulas).

Destacamos ainda os Saberes provenientes dos programas e livros didáticos utilizados no trabalho, que são: saber sobre o currículo dos anos iniciais. Por fim, há os Saberes provenientes de sua própria experiência na profissão, na sala de aula e na instituição onde atua: saber valorizar conhecimentos prévios dos alunos; saber disciplinar matemático; saber sobre dificuldades dos alunos quanto a conceitos, procedimentos e atitudes em matemática; saber refletir sobre as relações de práticas formadoras no curso (desconexão); saber contextualizar conteúdos através da história da matemática; saber usar tendências no ensino de matemática (materiais concretos, ensino por atividades, estudos psicológicos, resolução de problemas/exercícios, história da matemática, uso de recursos tecnológicos).

Vale lembrar que esses saberes temporais, diversificados e heterogêneos (TARDIF, 2002, TARDIF; RAYMOND, 2000) têm suas fontes sociais de aquisição na história compartilhada de cada um dos formadores; e são eles os frutos dessas experiências que transformam (LARROSA, 2002) e passam a reverberar a cada movimento da prática, assumindo movimentos distintos conforme similitudes e diferenças de cada trajetória.

São as semelhanças, bem como as diferenças de manifestação desses saberes, ao longo de narrativas sobre formação e prática, que permitem perceber o caráter maleável do saber docente que representa uma identidade formadora nos mesmos termos, entretanto única para cada formador que teve sua biografia reconstituída, de modo a revelar essas particularidades e suas imbricações.

Considerando o exposto, cabe reafirmar que os saberes dos professores formadores repercutem na maneira como pensam e conduzem suas práticas de formação de outros professores que ensinarão matemática dos anos iniciais. Em outros termos, foi possível evidenciar, por meio dessa pesquisa narrativa, que os saberes constituídos ao longo de cada trajetória de formação e desenvolvimento profissional são caracterizados por pensamentos, crenças, concepções, atitudes, conhecimentos diversificados e expressam os processos formativos vivenciados nos diferentes percursos, nas diferentes experiências. Esse lastro de saberes, portanto, justificam opções e abordagens na formação para a docência de professores para ensinar matemática nos anos iniciais de escolaridade.

\section{Considerações finais}

Após lançar nosso olhar sobre a história de vida e entretecer nela os saberes de cinco professores universitários, que formam professores para ensinar matemática nos anos inicias de escolaridade, revelamos por seus relatos como foram se constituindo tais saberes no percurso de formação de cada um deles e expressões desses saberes na prática formadora. Diante do que o estudo traz, retomamos Larrosa (2002), quando afirma não ser sujeito de experiência aquele a quem não foi possível aprender com a experiência e transformar-se com ela. De fato, cada experiência rememorada encontra ressonância naquilo que os professores formadores desta investigação são e fazem em suas práticas.

Os significados alcançados, portanto, demonstram virtualidades de transformações constitutivas e formativas ensejadas neste estudo, à medida que tratamos desses saberes de 
professores formadores evidenciados na trajetória vida, por meio do estudo biográfico. Cada qual, ao falar de si e contar a própria história, o fez com o olhar e com os saberes de hoje; num empreendimento retrospectivo que assume caráter reflexivo e por isso projetivo de novas aprendizagens, novos saberes e novas práticas, em face de se ter pensado intencionalmente sobre isso tudo para dar a conhecer. Assim também os leitores dessas histórias e dessas práticas estarão vendo e se vendo refletidos. Com isso, decorre a expressiva relevância de estudos narrativos na formação profissional.

A imersão nas histórias permitiu um olhar reflexivo sobre as experiências e fatores influenciadores do ingresso na formação profissional de cada participante. Na análise sobre opção pelo curso de licenciatura em matemática e sobre a adesão à docência foram apontados, dentre outros aspectos, os saberes matemáticos e os saberes pedagógicos da matemática em gênese na formação pré-profissional, ambos resultantes das variadas experiências e suas repercussões.

Ao incidir a análise sobre o percurso na socialização profissional nos cursos em que se licenciaram professores de matemática e em outros nos quais realizaram formações continuadas, bem como nas demais experiências, observamos que saberes foram expressos no que relataram, tais como: saber das dificuldades dos alunos/professores de pedagogia na matemática; saber sobre o currículo de matemática dos anos iniciais; saber não dissociar conteúdos e métodos; saber contextualizar o saber matemático e muitos outros que foram evidenciados no contexto de seus percursos formativos e que são reflexos de experiências vividas.

Na prática observada e contada por eles, esses saberes constituídos em cada história convergem no processo de condução das aulas e permitem em momentos combinados ou em momentos distintos, por um lado, oferecer um modelo pedagógico de apreensão de conteúdos matemáticos, necessários ao professor em formação com quem interagem. Por outro lado, possibilitam que este professor em formação possa desenvolver atitudes científicas e reflexivas relativas ao ensinar e ao aprender (confrontando e problematizando recursos didáticos, currículos, aspectos psicopedagógicos, históricos etc.), de modo geral, configurando um refletir sobre a docência, particularmente em matemática, e assim poder ver-se como professor em formação e não apenas como aluno.

Tal modo diferente de se ver na docência mostra-se um dentre os grandes desafios enfrentados pelos formadores de professores deste estudo; desafios tais que caminham pari passu com os processos formativos e autoformativos engendrados nesses contextos, sendo que, para tal, contam com o repertório de saberes que possuem e vêm sedimentando nos transcursos de suas ações formadoras.

\section{Referências}

ABRAHÃO, M. H. M. B. As narrativas de si ressignificadas pelo emprego do método autobiográfico. In: SOUZA, E. C. de; ABRAHÃO, M.H.M.B. (orgs.). Tempos, narrativas e ficções: a invenção de si. Porto Alegre: EDPUCRS, 2006.

BELO, E. S. V. Professores formadores de professores de matemática. Dissertação de Mestrado - Programa de Pós-Graduação em Educação em Ciências e Matemáticas. Universidade Federal do Pará, Instituto de Educação Matemática e Científica, Belém, 2012. (149 f) 
BENJAMIN, W. O Narrador: considerações sobre a obra de Nikolai Leskov. In: BENJAMIN, W. Magia e técnica, arte e política: ensaios sobre literatura e história da cultura. São Paulo: Brasiliense, 1994, p. 197-221.

BOGDAN, R. C; BIKLEN, S. K. Investigação qualitativa em educação: uma introdução à teoria e aos métodos. Porto: Porto Editora, 1994.

CONNELLY, M; CLANDININ, J. Relatos de Experiencia e Investigacion Narrativa. In: LARROSA, J. Déjame que te Cuente. Barcelona, Editorial Laertes, 2008.

CURI, A; PIRES, C. M. Pesquisas sobre a formação do professor que ensina Matemática por grupos de pesquisa de instituições Paulistanas. Educação Matemática Pesquisa, v. 10, n. 1, 2008. pp. 151-189.

DELORY-MOMBERGER, C. Biografia e educação: figuras do indivíduo-projeto. Trad. Maria da Conceição Passeggi, João Gomes da Silva Neto e Luis Pesseggi. Natal, RN: EDUFRN, 2008.

DEVLIN, K. J. O gene da matemática: o talento para lidar com números e a evolução do pensamento matemático. 5a. ed.. Trad. Sérgio Moraes Rego. Rio de Janeiro: Record, 2010.

FLORES, M. A. Algumas reflexões em torno da formação inicial de professores. Educação, v. 33, n. 3, p. 182-188, 2010.

GAUTHIER, C. et al. Por uma teoria da Pedagogia. Trad. Francisco Pereira. 2a. Ed. ljuí: Unijuí, 2006 (Coleção Fronteiras da Educação).

GONÇALVES, T. O. A Formação e Desenvolvimento Profissional de Formadores de Professores: O Caso dos Professores de Matemática da UFPA. Tese de Doutorado (Universidade de Campinas). Campinas, SP, 2000. (207 f.).

GONÇALVES, T. O; GONÇALVES, T. V. O. Reflexões Sobre Uma Prática Docente Situada: Buscando Novas Perspectivas Para a Formação de Professores. In: GERALDI, C; FIORENTINI, D; PEREIRA, E. (Org.) Cartografias do trabalho docente: professor(a)-pesquisador(a). Campinas: Mercado das Letras, 1998.

LARROSA, J. Notas sobre a experiência e o saber da experiência. Trad. João Wanderley Geraldi. Revista Brasileira de Educação, n. 19, p. 20-28, 2002.

LORTIE, D. C. Schoolteacher: a sociological study. Second edition. Chicago: The University Chicago Press, 1975.

MANFREDO, E. C. G. O professor de $1^{a}$ a $4^{a}$ série e o ensino de matemática: concepções e práticas na formação. Anais VIII ENEM, 2004.

MOITA, M. C. Percursos de formação e trans-formação. In: NÓVOA, A. (Org) Vidas de Professores. Porto: Porto Editora, 2000.

NÓVOA, A. (Org.). Os professores e as histórias da sua vida. In: NÓvOA, A. (Org) Vidas de Professores. Porto: Porto Editora, 2000.

NÓVOA, A. Formação de professores e profissão docente. NÓVOA, A. (Org.) Os professores e a sua formação. Lisboa: Dom Quixote, 1992. p. 13-33.

OLIVEIRA, A. T. Saberes e práticas de formadores de professores que vão ensinar matemática nos anos iniciais. Tese de Doutorado (PUC-RJ). Rio de Janeiro, 2007. 
PEDROSA. E. M. P; LEITE, L. S; ARAGÃO, R. M. Formação profissional do professor de matemática: saberes essenciais que emergem de relatos docentes. Amazônia: Revista de Educação em Ciências e Matemáticas, v. 8, n. 16, p. 159-173, 2012.

SACRISTÁN, J. G. Consciência e acção sobre a prática como libertação profissional dos professores. In: NÓVOA, A. Profissão Professor. 2a. ed. Lisboa: Editora Porto, 1995.

SERRAZINA, L.. A Formação para o ensino da Matemática na Educação Pré-escolar e no $1^{\circ}$ ciclo do ensino básico. Cadernos de Formação de Professore, n. 3. Porto: Porto Editora e INAFOP, 2002.

SHULMAN, L. Conocimiento y enseñanza: fundamentos de la nueva reforma. Profesorado Revista de curriculum y formación del profesorado, n. 9, v. 2, 2005.

SHULMAN, L. Entrevista concedida à Daniela Ingui. Revista Comciência - Revista Eletrônica de Jornalismo Científico, em mai/2010.

TARDIF, M. Saberes docentes e formação profissional. 2a. ed. Petrópolis: Vozes, 2002.

TARDIF, M. Saberes profissionais dos professores e conhecimentos universitários elementos para uma epistemologia da prática profissional dos professores e suas consequências em relação à formação para o magistério. Revista Brasileira de Educação, n. 13, 2000.

TARDIF, M.; RAYMOND, D. Saberes, tempo e aprendizagem do trabalho no magistério. Educação \& Sociedade, v. 21, n. 73, 2000. 